\title{
INMEDE DEKOMPRESIF CERRAHI
}

\author{
Refik KUNT*, Erdem YAKA*, Vesile ÖZTÜRK*, Ercan ÖZER**, Kürşad KUTLUK* \\ *Dokuz Eylül Üniversitesi Tıp Fakültesi Nöroloji Ana Bilim Dalı, İZMìR \\ **Dokuz Eylül Üniversitesi Tıp Fakültesi Nöroşirurji Ana Bilim Dalı, İZMìR
}

\section{ÖZET}

AMAÇ: Merkezimizde dekompresyon cerrahisi uygulanan akut inme olgularını sunmak ve sonuçları son literatür bilgileriyle birlikte tartışmak.

GEREÇ ve YÖNTEM: Ağustos 2010 - Şubat 2012 tarihleri arasında Dokuz Eylül Üniversite Hastanesi Nöroloji servisinde izlenen ve 1-11 gün içinde medikal tedaviye rağmen klinik progresyon gelişen 4 kadın, 4 erkek toplam 8 hastaya dekompresyon cerrahisi uygulandı. Hastaların altısına geniş hemikraniektomi + duraplasti, ikisine suboksipital kraniektomi operasyonu yapıldı.

BULGULAR: Orta serebral arter enfarktı olan bir olgu, gelişen yaygın arka sistem enfarktı nedeniyle, bir olgu ise operasyon sonrası gelişen enfeksiyon nedeniyle kaybedildi. Postoperatif izlem süresi 35-95 gün olan diğer hastalarda mRS; iki hastada 2, iki hastada 4 ve birer hastada 3 ve 5 olarak değişiklik gösterdi.

SONUÇ: Olgu sayımız sınırlı olsa da, sonuçlarımız, cerrahi tedavinin hem mortaliteyi azalttığı, hem de bazı hastalarda fonksiyonel iyileșmeyi sağladığını göstermektedir.

Anahtar Sözcükler: İnme, cerrahi.

\section{DECOMPRESSIVE SURGERY IN STROKE}

\section{ABSTRACT}

OBJECTIVE: Our aim was to present the acute stroke cases carried out decompression surgery and to discuss our results with literature.

MATERIAL and METHODS: Decompression surgery was carried out in 8 patients including 4 women and 4 men who followed and clinically progressed despite the medical treatment within 1-11 days in Dokuz Eylül University Hospital Neurology Clinic between August 2010 and February 2012. Extensive hemicraniectomy+duraplasty were performed in 6 patients and suboccipital craniectomy was performed in 2 patients.

RESULTS: One patient with middle cerebral artery infarction died because of widespread posterior system infarction and additionally one patient died due to infection following operation. In remaining patients followed for 35 to 95 days postoperatively, mRS was change 2 points in 2 patients, 4 points in 2 patients, 3 points in 1 patient and 5 points in 1 patient.

CONCLUSION: Although sample size was limited, our results were showed that surgical treatment reduces mortality and helps to provide the functional recovery in some patients.

Key Words: Stroke, surgery.

\section{GíRiş}

İnme nörolojik acil bir durumdur, gelişmiş ülkelerde kalp hastalıkları ve kanserden sonra gelen üçüncü mortalite nedeni ve birinci sırada gelen sakatlık nedenidir. 2010 Dünya sağlık örgütü

verilerine göre dünyada her yıl 15 milyon insan inme olup üçte biri mortalite ile sonlanmakta, üçte birinde ise kalıcı sakatlık oluşmaktadır (1). Tüm inmeler içinde iskemik inme \%80 (\%75-

\footnotetext{
Yazışma Adresi: Doç. Dr. Erdem Yaka Dokuz Eylül Üniversitesi Tıp Fakültesi Nöroloji Anabilim Dalı, İzmir.

Tel: $02324124066 \quad$ E-posta: erdem.yaka@deu.edu.tr

Gelis Tarihi: 11.10.2012 Kabul Tarihi: 06.05.2013 Accepted: 06.05 .2013

Bu makale şu şekilde atıf edilmelidir: Kunt R, Yaka E, Öztürk V, Özer E, Kutluk K. İnmede dekompresif cerrahi. Türk Beyin Damar Hastalıkları Dergisi 2014; 20 (1): 13-17. doi: 10.5505/tbdhd.2014.03753.
} 
80), intraserebral hemoraji (İH) \%15 (\%10-15), subaraknoid kanama (SAK) \%5 (\%5-10) oranında görülmektedir (2). Supratentorial yerleşimli beyin damar hastalıklarından (malign orta serebral arter (OSA) infarktı, geniş kortikal ve lober hematomlar) sonra gelişen beyin ödemi unkal ve transtentorial herniasyona, infratentorial yerleşimli beyin damar hastalıklarından (serebellar infarkt, serebellum ve beyin sapı hematomları) hidrosefali, beyin sapı basısı, transforaminal tonsiller herniasyon gibi mortaliteyi arttırıcı klinik tablolara neden olurlar (3). Hangi hastaların dekompresyon cerrahisinden daha fazla fayda göreceğini inmenin başlangıcında tahmin etmek oldukça zor olmasına rağmen genel olarak kabul edilen radyolojik ve klinik olarak malign ödem için yüksek riskli olan hastalarda medikal tedaviye rağmen kitle etkisinde artış devam etmekteyse, dekompresyon cerrahisi yaşam kurtarıcı bir tedavi seçeneği olmaktadır $(4,5)$. Bu yazıda, merkezimizde dekompresyon cerrahisi uygulanan akut inme olguları sunularak, operasyondan sonraki izlem süreleri, sağ kalım oranları ve dizabilite skorları son literatür bilgileriyle birlikte karşılaştırıldı ve tartışıldı.

\section{GEREC VE YÖNTEM}

Değerlendirmeye Ağustos 2010 - Şubat 2012 tarihleri arasında Dokuz Eylül Üniversite Hastanesi Nöroloji kliniğinde izlenen ve inme tanısı alan 8 hasta alındı. Değerlendirmeye dahil edilen hastaların ayrıntılı anamnezleri, özgeçmişleri ve nörolojik muayeneleri kaydedildi. Görüntüleme yöntemlerinden beyin tomografisi (BT), Diffuzyon MRG (Manyetik rezonans görüntüleme), BT/MRG Anjiografi ile lezyonlar saptand,, yerleşim yerleri belirlendi. İnmeler infarkt alanının yerleşim yerine göre değerlendirildi. Olguların klinik ve radyolojik değerlendirmeler sonucu yüksek herniasyon riski altında olduğu için Dokuz Eylül Üniversite Hastanesi Nöroşirurji Anabilimdalı tarafından konsulte edilerek izleme alındı. Hastalara öncelikle medikal tedavi uyguland. Medikal tedaviye rağmen hayatı tehdit eden beyin ödemi, kitle etkisi ve doku şiftinde artış saptanması durumunda herniasyon gelişmeden nöroşirurji anabilimdalı tarafindan dekompresyon cerrahisi uyguland. Fonksiyonel bağımlılığı saptamada ve iyileșmeleri değerlendirmede modifiye Rankin Skalası (mRS) kullanıldı. Operasyondan sonraki izlem süreleri, mortalite oranları ve dizabilite skorları saptandı.

\section{BULGULAR}

1-11 gün içinde medikal tedaviye rağmen klinik progresyon gelişen 4 kadın, 4 erkek toplam 8 inme hastasina dekompresyon cerrahisi uygulandı. Yaşları 31-85 arasında değişen olguların, dördünde orta serebral arter (OSA) infarktı, ikisinde serebellar infarkt, birinde venöz infarkt (hemorajik transformasyon özelliği olan), birinde lober serebral kanama saptandı. Cerrahi öncesi Modifiye Rankin Skoru (mRS) 7 hastanın 5, 1 hastanın 4 olarak değerlendirildi. Olguların tümü Dokuz Eylül Üniversite Hastanesi Nöroşirurji Anabilimdalı tarafından nöroloji kliniğindeki izlem sırasında gelişen progresyon sonrası konsültasyon sonucu değerlendirildi ve altısına geniş hemikraniektomi + duraplasti , ikisine suboksipital kraniektomi operasyonu uyguland (Tablo 1). Geniş hemikraniektomi uygulanan iki hastanın beyin BT'leri Resim 1 ve 2'de görülmektedir.

Orta serebral arter infarktı olan bir olgu sonradan gelișen yaygın arka sistem infarktı, bir olgu ise operasyon sonrası gelişen enfeksiyon nedeniyle kaybedildi. Postoperatif izlem süresi 3595 gün olan diğer hastalarda mRS; iki hastada 2, iki hastada 4 ve birer hastada 3 ve 5 olarak değişiklik gösterdi (Tablo 1).

\section{TARTIŞMA}

Yer kaplayıcı özellikte gerek serebral gerekse serebellar geniş hemisferik infarktlarda konvansiyonel medikal tedaviler intrakranial basincı azaltmakta yetersiz kalabilmektedir. Dekompresyon cerrahisinde amaç; kraniyum kemiğinin bir kısmını kaldırarak dura materi açmak ve ödemlenmiș infarktlı beyin dokusunun dişa doğru genişlemesine imkan sağlamaktır. Böylelikle doku şifti ve ventrikül kompresyonu ile sağlıklı beyin dokusuna olacak olumsuz etki engellenecektir $(6,7)$. İntrakraniyal basıncın normal seviyelere inmesi ile birlikte serebral kan akımında artış, serebral perfüzyon basıncında düzelme ve halen sağlıklı kalmış beyin dokusunda daha iyi oksijenizasyon olacaktır (8).

Dekompresyon cerrahisinin fonksiyonel düzelme ve yaşam kalitesi üzerine olumlu etkisi olmadığını iddia eden eski çalışmaların aksine son yıllarda uygun hastalara yapılan cerrahi sonrası afazi gibi kortikal bulgularda dahi kısmi oranda düzeldiği gösterilmiştir $(6,9)$ İskemik inme üzerine yapılan çalışmalar genel olarak malign OSA 
Tablo 1. Dekompresyon cerrahisi uygulanan olguların özellikleri.

\begin{tabular}{|c|c|c|c|c|c|c|c|}
\hline & Olgu & Yaş & Cinsiyet & Tanı & $\begin{array}{l}\text { Cerrahi } \\
\text { zamanı }\end{array}$ & $\begin{array}{c}\text { Cerrahi öncesi / } \\
\text { sonrası (3.ay) mRS }\end{array}$ & $\begin{array}{c}\text { Hastanede } \\
\text { izlem süresi }\end{array}$ \\
\hline 1 & S.T. & 50 & $\mathrm{E}$ & Sağ serebellar infarkt & 2 gün & $4 / 6$ (exitus) & 14 gün (exitus) \\
\hline 2 & N.Ç. & 74 & $\mathrm{~K}$ & $\begin{array}{l}\text { Sol frontoparyetal lober hemorojik } \\
\text { infarkt }\end{array}$ & 4 gün & $5 / 3$ & 39 gün \\
\hline 3 & N.M. & 54 & E & Bilateral serebellar infartk & 4 gün & $5 / 4$ & 99 gün \\
\hline 4 & M.G. & 58 & $\mathrm{~K}$ & Sağ ACA - MCA infarktı & 10 saat & 5 / 6 (exitus) & 10 gün (exitus) \\
\hline 5 & A.A. & 85 & $\mathrm{E}$ & Sol MCA' da hemorojik infarkt & 11 gün & $5 / 2$ & 62 gün \\
\hline 6 & B.B. & 59 & E & Sağ MCA infarktı & 7 gün & $5 / 5$ & 83 gün \\
\hline 7 & E.U.* & 31 & $\mathrm{~K}$ & Sol frontalde hemorajik venöz infarkt & 2 gün & $5 / 2$ & 70 gün \\
\hline 8 & S.K. & 68 & $\mathrm{~K}$ & Sağ MCA infarktı & 2 gün & $5 / 4$ & 37 gün \\
\hline
\end{tabular}

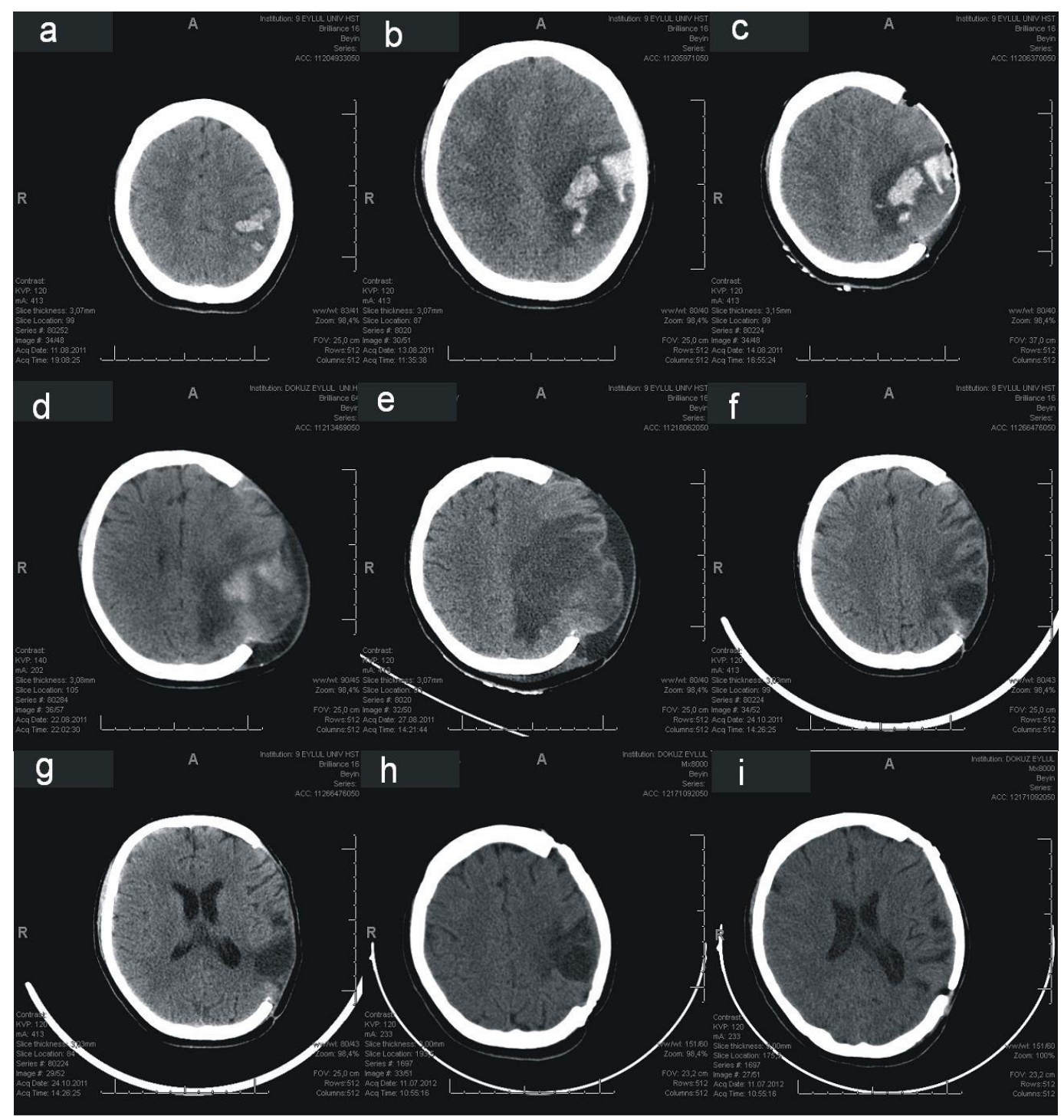

Resim 1. a-b. Acil servisine bașvurusundan 5 gün önce $C / S$ ile doğumu öyküsü ve hemen ardından bașlayan baș ağrısı olan olgu ani gelișen sağ yan güçsüzlüğü nedeniyle incelenen beyin BT' sinde sol parietal lobda santral sulkus posterior yerleşimli ödem etkisi saatler içinde belirgin hale gelen parankimal hematom ve komşuluğunda posterior superfisyel frontal vende trombüs ile uyumlu hiperdens görünüm saptandı. mRs:5 c. 3 gün sonra yaklaşık $1 \mathrm{~cm}$ çapında ödem ve orta hatt kayma saptandı. Dekompresyon cerrahisi uygulandı. d-e. Sirasıyla dekompresyon cerrahisinden 7 gün ve 10 gün sonraki görüntüler. f-g. 3 aylık nöroloji servisi izlemi sonrası taburculuk öncesi görüntüler mRs:2 h-i. Operasyon sonrası 11. ayda otojen kranioplastı yapıktan sonraki görüntüler. mRs:1 


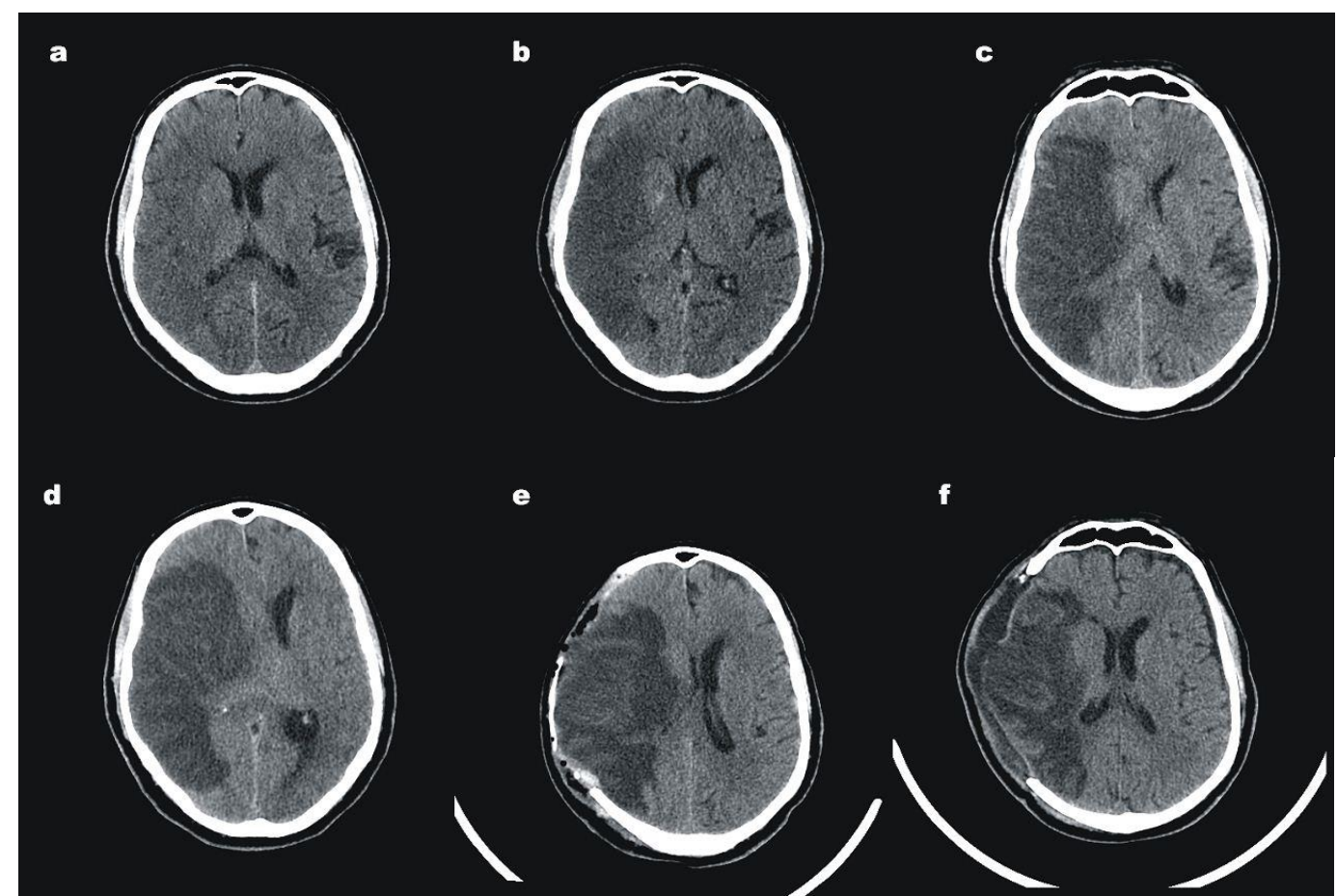

Resim 2. a- Ani gelişen sol yan güçsüzlüğü gelişen olgunun başvuru beyin BT' sinde sağ OSA sulama alanında hiperakut enfarktla uyumlu sulkuslarda silikleșme saptandı. b- 1. günde sağ OSA sulama alanındaki enfarkt alanının daha belirginleștiği, enfarkt çevresindeki ödeme sekonder olarak sağ lateral ventrikül orta hatta minimal kaydığı saptandı. c- 4. günde sağ lateral ventrikülün silindiği, orta hatta 10 milimetrelik kayma meydana geldiği saptandı. d6. günde orta hatta yaklaşık $20 \mathrm{~mm}$ boyutunda bir kaymaya ek olarak sol lateral ventrikülün dilate göründüğü saptandı. mRs:5 olan hastaya dekompresyon cerrahisi uygulandı. e- Dekompresyon cerrahisi sonrası 1. günde sağ lateral ventrikülün tekrar görünür olduğu, orta hattaki kaymanın $10 \mathrm{~mm}$ 'ye gerilediği, sol lateral ventrikül hacminin azaldığı saptandı. f- Dekompresyon cerrahisi sonrası 14. günde beyin parankiminin geniş kranioktomi defektinden herniye olduğu, orta hattaki kaymanın kaybolduğu, sağ ve sol lateral ventriküllerin normal sınırlarda olduğu saptandi.

infarktlarına yöneliktir. Malign OSA infarktlarında dekompresyon cerrahisi ile ilgili olarak son 10 yll içinde 3 randomize Avrupa çalışmasının sonuçları yayınlanmıştır. DECIMAL çalışmasında randomize edilen 38 hastada mortalite dekompresyon uygulanan grupta medikal tedavi grubuna kıyasla birinci haftada $\% 5$ e karşsllı $\% 67$ ve dördüncü haftada \%16 ya karșllk \%33 oranında belirgin düşük saptanmıștır (10). 32 hastanın randomize edildiği DESTINY çalışmasında bir ayın sonunda dekompresyon yapılan grupta mortalite oranı $\% 12$, cerrahi uygulanmayan grupta \%53 saptanmıștır (11). HAMLET çalışmasında 64 hasta randomize edilmiştir. Ondördüncü günde mortalite dekompresyon uygulanan grupta \%16, uygulanmayan grupta \%56 bulunmuştur (12). Bu üç çalışmanın 93 hasta içeren havuzlanmış verileri doğrultusunda cerrahi grupta mortalitede belirgin azalma gösterirken (sağ kalım cerrahi uygulananlarda \%78; kontrol grubunda \%29 ARA: \% 50) fonksiyonel sonuçlar bağlamında değerlendirme yapıldığında eğer mRS $\leq 3$ alınırsa anlamlı bir iyileşme göstermemiştir. (dizabilite cerrahi uygulananlarda \%43; kontrol grubunda \%21 ARA: \%23) Ancak fonksiyonel sonuçların değerlendirilmesinde $\mathrm{mRS} \leq 4$ alındığında anlamlı iyilik hali olduğu belirtilmiştir (dizabilite cerrahi uygulananlarda \%75; kontrol grubunda \%24 ARA: \%50). Sonuç olarak kontrol grubu ile karşılaştırıldığında dekompresyon cerrahisi uygulanan grupta sağ kalım her iki hastadan birinde, fonksiyonel sonuçların değerlendirilmesinde $\mathrm{mRS} \leq 4$ alındığında dizabilite ise her iki hastadan birinde görülmüștür (13). İntraserebral kanamalarda dekompresyon cerrahisi ile ilgili olarak 27 ülkede 83 merkezin katıldığı 1033 hastanın randomize STICH (Surgical Trial in Intracerebral Haemorrhage) çalışması ön plana çıkmaktadır. En az $2 \mathrm{~cm}$ genişliği olan supratentoriyal hematomlu olgular erken cerrahi (ortanca 30) ve medikal tedavi gruplarına randomize edilmiştir. Sonuçta cerrahi planlanan 
hastalardan \%6 sına cerrahi hiç yapılmamış sadece medikal tedavi uygulanmışken medikal gruptaki hastaların \%26 sına daha sonra cerrahi uygulanmış ve yüksek çapraz geçiş oranına neden olmuştur. Sonuçta 180. günde iyi fonksiyonel sonuç cerrahi grupta \%24 medikal grupta \%26, mortalite ise cerrahi grupta \%37, medikal grupta \%36 saptanmıș ve istatiksel farklılık göstermemiştir $(14,15)$.

Olgularımız malign OSA infarktı, hemorajik transformasyon özelliği olan venöz infarkt ve hemorajik infarkt olarak 3 grup altında incelenebilir. Ancak literatür ile karşılaştırıldığında olgu sayımız sınırlıdır. Bu nedenle bütün olarak ele alırsak dekompresyon yapılan hastalarda sağ kalım \%75 (n: 6) olup ve literatür ile yaklaşık olarak benzerdi. Fonksiyonel sonuçların değerlendirmesinde mRS $\leq 3$ alınırsa iyilik hali \%37,5 (n: 3), mRS $\leq 4$ alınırsa \%62,5 (n:5) olup literatür bilgilerinden daha düșük oranlardaydı.

Sonuç olarak, seçilmiş hastalarda dekompresyon cerrahisi yaşam süresini uzatabilir ve iyi fonksiyonel sonuçlara neden olabilir. Hekimler mortalitenin azalmasına rağmen genel olarak hastalar orta-ağır derecede özürlü kalabileceği için hasta yakınlarına cerrahi sonrası gelişebilecek durum hakkında detaylı bilgi vermelidir (6). Dikkatli hasta seçimi ve erken cerrahi uygulamaları ile iyi fonksiyonel sonlanım sağlanabileceği unutulmamalıdır.

\section{KAYNAKLAR}

1. World Health Organization. 2010, Statistical Annex, in The World HealthReport 2010, WHO, Geneva, Switzerland.

2. Tarun Dua, Aleksandar Janca, Anna Muscetta. Stroke. In: Aarli JA, Avanzini G, Bertolote JM (Eds.). Neurological disorders Public Health Challenges. WHO 2006;151-63.

3. Katzman R, Clasen R, Klatzo I, et al. Brain edema in stroke: Study group on brain edema in stroke. Stroke 1977; 8:51240.
4. Kilincer, C., Asil, T., Utku, U., Hamamcioglu, M.K., Turgut, N., Hicdönmez, T., Simsek, O., Ekuklu, G. and S. Cobanoglu, "Factors Affecting the Outcome of Decompressive Craniectomy for Large Hemispheric Infarctions: A Prospective Cohort Study," Acta Neurochir. (Wien), 147,587-594 (2005).

5. Fung C, Murek M, Z'Graggen WJ, et al. Decompressive Hemicraniectomy in Patients With Supratentorial Intracerebral Hemorrhage. Stroke. 2012;43:3207-3211.

6. Balci K. Akut Orta Serebral Arter İnfarktlı Hastalarda Dekompresif Hemikraniyektomi Tedavisi: derleme. Turkiye Klinikleri J Neurol-Special Topics 2012;5(2):54-60.

7. Woertgen, C.; Erban, P.; Rothoerl, R. D.; Bein, T.; Horn, M.; Brawanski, A. Acta. Quality of life after decompressive craniectomy in patients suffering from supratentorial brain ischemia. Neurochirurgica vol. 146 issue 7 July, 2004. p. 691-695.

8. Stephan A. Mayer et al. Hemicraniectomy A Second Chance on Life for Patients With Space-Occupying MCA Infarction Stroke. 2007; 38: 2410-2412.

9. Asil T, Utku U, Balci K, Kilincer C. Recovery from aphesia after decompressive surgery in patients with dominant hemispheric infarction. Stroke 2005;36(10):2071.

10. Jüttler E, et al. Decompressive surgery for the treatment of malignant infarction of the middle cerebral artery (DESTINY) - a randomized, controlled trial. Stroke. 2007; 38: 2518-2525.

11. Vahedi K, Vicaut E et al. A sequential design, multicenter, randomized, controlled trial of early decompressive craniectomy in malignant middle cerebral artery infarction (DECIMAL trial) Stroke. 2007; 38: 2506-2517.

12. Hofmeijer J, Amelink GJ, et al. ; HAMLET investigators. Hemicraniectomy after middle cerebral artery infarction with life-threatening Edema trial (HAMLET). Protocol for a randomised controlled trial of decompressive surgery in space-occupying hemispheric infarction. Trials. 2006; 7: 29.

13. Vahedi K, Hofmeijer J et al. for the DECIMAL, DESTINY, and HAMLET investigators. Early decompressive surgery in malignant infarction of the middle cerebral artery: a pooled analysis of three randomized controlled trials. Lancet Neurol. 2007; 6:315-322.

14. Mendelow AD, Gregson BA et al.; STICH investigators. Early surgery versus initial conservative treatment in patients with spontaneous supratentorial intracerebral haematomas in the International Surgical Trial in Intracerebral Haemorrhage (STICH): a randomised trial. Lancet. 2005; 365 (9457): 387-97.

15. Topcuoglu MA, Arsava EM. İntrakraniyal kanamalarda tanı ve tedavide yenilikler: derleme. Türkiye Klinikleri J NeurolSpecial Topics 2012;5(2): 61-74. 